Purdue University Purdue e-Pubs

1988

\title{
Performance Analysis of Capacity Control Devices for Heat Pump Reciprocating Compressors
}

Edsonei Pereira Parreira

Universidade Federal de Uberlandia

Jose Alberto dos Reis Parise

Pontificia Universidade Catolica do Rio de Janeiro

Follow this and additional works at: https://docs.lib.purdue.edu/icec

Parreira, Edsonei Pereira and Parise, Jose Alberto dos Reis, "Performance Analysis of Capacity Control Devices for Heat Pump Reciprocating Compressors" (1988). International Compressor Engineering Conference. Paper 666.

https://docs.lib.purdue.edu/icec/666

This document has been made available through Purdue e-Pubs, a service of the Purdue University Libraries. Please contact epubs@purdue.edu for additional information.

Complete proceedings may be acquired in print and on CD-ROM directly from the Ray W. Herrick Laboratories at https://engineering.purdue.edu/ Herrick/Events/orderlit.html 


\author{
Edgonei Pereira Parreira \\ Aggociate Professor \\ Universidade Federal de Uberlandia \\ 38400 Uberlandia BRAZIL \\ José Alberto dos Reis Parige \\ Associate Professor \\ Pontiflcia Universidade Catblica do Rio de Janeiro \\ 22453 Rio de Janeiro BRAZIL
}

\title{
ABSTRACT
}

The present payer is concerned with the study of the application of capacity control devices on heat pump reciprocating compresgors. Five typical control systems have been studied: variable speed, variable clearance volume, by-pass of the discharge gas, throttling of the suction gas and suction valve cut-off, A sigulation model was developed for the analyais.

\section{INTAODUCTION}

Capacity modulation of reciprocating compressors has been the subject of intensive development in the last two decades. The adjustment of compressor throughput, at low cost and reliably, to the varying demand of plants in the procesg and manufacturing industrie日 has now become a necessity. One particular application of reciprocating compressors concerns refrigeration and heat pump systens. The heat pump can be regarded ag a variation of the refrigeration plant, with interegt being centered on the delivery of heat on the condenser, rather than in the extraction of heat so as to sustain subatmospheric temperatures at the evaporator. Nonetheless the basic thermodynamic cycle (vapour-compregaion) ia the same for both syatems. A feature of heat pump operation is that the temperature difference between the heat source and heat sink is likely to be more variable than in refrigeration. This regults in a wider range of inlet and delivery pressures for the compressor. The thermal load, from the heat source, is also likely to vary considerably [1]. As a result, compresgor capacity modulation becomes almost an essential part of heat pump operation. The objective of the pregent paper is to study the application of capacity control devices on heat pump reciprocating compressors.

There is available a oreat variety of compressor capacity control devices and a number of gurveys can be found in the literature [2,3]. According to Verma [3] capacity modulation can be divided in three basic groups: stepped, stepless and composite control. This is only one criterion as they may be grouped in terms of internal or external control [2], or in regard to the point of appljeation (suction/discharge valve, cylinder volume or drive actuating contro1). In addition to the traditional start-gtop regulation the followng devices are studied in the literature: compreasor uncoupling, variable speed [4], variable clearance volume $[5,6]$, variable cylnder volume $[7]$, suction valve cut-off $[8]$, suction valve unloading $[9,10,11]$, blocked auction [12], top head unloading (1nternal gas by-pasging) [13,14], suction throttling [15], digcharge gas by-passing [15]. The list is not complete as there is a nuber of variations and combinationg of the bagic devices [2].

In the present paper a numerical gimulation model was employed to analyae five devices: variable speed, variable clearance volume, by-pass of the discharge gas, throtting of the suction gas and suction valve cut-off. To find the mogt suitable device several aspects should be taken into account. They would include the energy convergion efficiency, type of application, cost and reliability, to name but a few. Therefore, it should be stregged that the objective of this paper is regtricted to the thermodynamic performance of the devices. A similar analygis has been carried out by Haseltine and Qvale [16] for three different capacity reduction methods. Results vere limited by the simplifications made on the compressor model. As far as capacity control in heat pump is concerned, the majority of the papers $[17,18,19]$ concentrate on var iable compressor speed. 
The heat pup under consideration is presented schematically in Figure 1 . It is of the vapour-compregsion type and consists of an open-type reciprocating compressor, a water-cooled condenser, evaporator and expansion valve. For the purposes of the present study, it is assumed that the evaporator operates at constant pressure, supplying vapour at a constant deoree of euperheat. This assumption limits the gimulation to the compressor and condeneer unit. Therefore, vapour conditions at the compressor inlet are supplied to the model as input data. In addition to have a less complex model, the reason for this simplification was that it allowed the study of the sole effect of compresgor capacity modulation on the condenser water outlet temperature.

A detailed model for the compressor was utilized. It follows traditional methoda of computer simulation for reciprocating compressors, by corsidering the cylinder space as a control volume, Figure 1 , with two flow boundaries (valves), a moving boundary (piston) and heat trangfer across its gurface (dQ/dt). The energy equatıon, in its time-derivative form, 15 applied to the control volume, leading to.

$\frac{d P}{d t}=-\frac{1}{v}\left[\frac{d Q}{d t}-m \frac{d h}{d t}-\left(h-h_{i}\right) \frac{d m}{d t}\right]$

where $p$ and $V$ are the instantaneous cylinder pregsure and volume and $w$ and $h$ the gas specific enthalpy and mags. Inteoration of equation (1) gives the variation of cwlinder pressure with time. Further equations are required for the determination of the righthand side terms of (1). They are: the heat transfer equation (dQ/dt), kinematics equation $(V)$, equation of state $(m)$, enthalpy equation $(h)$ and valve mass flow rate equation (dm/at). Real gas equations [21] are used for the evaluation of $m$ and $h$. Pressure fluctuations in the inlet and delivery ducts are ignored, so that evaporating and condensing pressures are considered to be ateady throuphout the cycle. For the mass flow rate through the valves, one-dimensional flow is asgumed. The model algo requires a detailed information on the valve system, which includes: valve and sprino masses, spring stiffness, valve pre-load, viscous damping factors, draq and digcharge coefficients, maximu digplacement and flow areas. One original aspect of the model [20] concerns the peneralized equation for the effective flow area, $A_{f}$, as related to
valve lift, $y$. $A_{f}=c_{d}{ }_{\max } \sin \left[\frac{\pi}{2}\left[\frac{y}{y_{\max }}\right]\right]$

Equation (2) was found to apree well with experimental data from several authors, Figure 3. Valve lift and presgure difference are related by the dynamicg of valve motion (one-degree of freedow model). In addition, energy and mags conservation equations are applied to account for the presence of guction throtling or gas bypaasing. There is, of courge, no need to model variable speed or variable clearance volume, as this can be done simply by altering the input data. Modelling the guction valve cut-off mechanism is done by imposing an instantaneous closure of the valve (ie, zero displacement). The condenser is modelled by the usual three heat exchanger equations (heat balances in water and refrigerant streams and the log-mean temperature
difference equation).

The model bagic algorithm is presented below:

a) With suction conditions ( $T$ and $P$ ) and an eatimated diacharge preagure perform the compressor model, in order to provide the refrigerant mass flow rate and the
discharge temperature.

b) From condenser inlet conditiong determine the condensing and water outlet temperatures and the thermal power output.

c) Compare the estimated condensing pressure with that uged for the compressor model. If convergence in $g_{\text {cd }}$ has not been achieved return to (a) with a new value.

\section{RESULTS AND DISCUSSION}

The model was applied to a typical medium-sized heat pump system. A two-cylunder compressor operated at a nominal speed of $1500 \mathrm{rpm}$, wh th suction at $10^{\circ} \mathrm{C}$ and 3 bar. Clearance ratio was set at 0.0363 with a bore/atroke relation of $0.0667 / 0.0635$ m. The
condenser was assumed to have condenser was assumed to have an overall heat transfer coefficient of $0.4 \mathrm{kN} /{ }^{\circ} \mathrm{C}$ and 2 
$\mathrm{m}^{2}$ of heat transfer area. Water inlet temperature was kept at $30^{\circ} \mathrm{C}$. Refrigerant-12 was taken as the working fluid.

In a first comparative analysis, figure 5 , the compressor was supposed to run at a constant presgure ratio of 5 , with the mass flow rate ranging from 100 to 30 (mass flow ratio of 0.3$)$ of the degion point. Figure 5a depicts the variation of the volumetric efficiency with the mass flow ratio. It can be seen that three of the capacity control devicea (suction throttling, variable clearance volume and euction valve cut-off) do act on the compreasor volumetric efficiency. This is not the cage for the gas by-passing, as the efficiency is defined in terms of the mass flow rate at the discharge port (d), Figure 4a. As for the variable speed device, lower phatt speeds resulted in reduced gas flow losses, leading to an increase in the volumetric efficiency.

With the exception of gas by-passing, where practically the same quantity of gas must always circulate through the compressor, all devices presented a reduction on power consumption for lower mass flow ratiog, Figure 5b. However, this situation changes when the comparison is made in terms of the specific power congumption (Watts per $\mathrm{kg} / \mathrm{s}$ of gas), Figure $5 \mathrm{c}$. Variable clearance volune and variable speed stand out as the most effective methods, with suction throttling and suction valve cut-off pregenting the worst results. Such behaviour will directly affect the heat pump performance.

One important parameter for heat pump applicationg refers to the coupressor discharge temperature, which must not exceed the refrigerant thermal gtability Iimit Again, Fiqure 5d, variable clearance volume and variable epeed pregented, by far, the best results. In fact, the other devices presented a serious tendency of increasing the discharge temperature at reduced mass flow ratios. Without a proper desion this could jeopardize the entire control effort.

In a second analysis the model was employed to simulate the operation of the heat pump with three different water flow rates $(0.154,0.24$ and $0.49 \mathrm{~kg} / \mathrm{s})$, each providing, at the degign point, an outlet temperature of $60^{\circ} \mathrm{C}, 50^{\circ} \mathrm{C}$ and $40^{\circ} \mathrm{C}$, regpectively. From the predicted results, Figure 6 , it can be concluded that, in theory, all five devices were able to provide a wide range of condenser outlet tenperatures. Water inlet temperature, for all cases of Figure 6 , was $30^{\circ} \mathrm{C}$.

Figures 7 and 8 smmarize the heat pump analygis, showing the variation of the heating coefficient of performance and the compressor digcharge temperature with the condenser water outlet temperature. Clearly, variable clearance volume and variable speed presented the best result: water temperature reduction with an increasing $C O P$ and within gafe limits for the refrigerant stability. In fact, results from Figure 7 have been anticipated by Figure 5c, with the difference that the cowpressor pressure ratio, dependant on the condenging pressure, is now varying. Not surprinsingly, the devices that make use of irreversible procesges, such as throttling (ST,BP) and gas mixing (BP), presented the worst performances, not only in respect to the COP but also regarding the temperature levels achieved at the digcharge. As for the suction valve cut-off method, cop figures were not adversely affected, eventhough Figure 8 shows that the discharge temperature may be cause for concern.

\section{CONCLUDING REMARKS}

The main objective of the paper was to assess how the condenser water outlet temperature could be controlled by means of varying the compresgor capacity. For that a simulation model for the heat pump was developed. It included the model for the compressor 1 tegelf (with constant intake and delivery pressures, valve dynamics and heat trangfer across cylinder walls) as well as a simplified model for the condenger.

To compare all five mechaniams two parameters have been selected: the heat pump coefficient of performance and the compressor discharge temperature, this one being important in the refrigerant thermal stability aspect. Generally it has been concluded that best regults were obtained with variable speed and variable clearance volume. suction throttling and digcharge gas by-pasaing, being highly irreversible procegsea, presented the worst performances. 
1. Parige, J.A.A., Heat Pumpg: A Survey on Heat Sources, Proc VIII Brazilian Cong Mech Eng, pp 213-216, São José dos Campos, Brazil, 1985.

2. Holdack-Jangsen,B. and Kruse, H., Continuoug and Discontinuous Capacity Control for High Speed Refrigeration Conpreseorg, Prof Purdue Comp Tech Conf, pp 67-75, 1984.

3. Verma, J.C., Optimum Utilization of Capacity Control Devices in Reciprocating Compresgors, Proc Purdue comp Tech Conf, pp 509-520, 1986.

4. Bredensen. A.M. and Paul. J., Effectg of Speed Control on the Valve performance and on the Eneroy Efficiency of Heat Pump Reciprocating Compressors, proc Antriebe fur Warme Pumperl, pp 69-74, West Germany, 1979.

5. Yun, K.W. and Reege, $\mathrm{L}_{n}$, Over-Reexpansion as a Meang of Compresgor Capacity Modulation, Proc Purdue Comp Tech Conf, pp 61-66, 1984.

6. TuYmer, W.J., Steplesg Variable Capacity Control, Proc Puroue Comp Tech Conf, pp 61$66,1974$.

7. Bartolini,C.M and Vincenz1,G., New Internal Capacity Control for Reciprocatino Compreasorg, Proc purdue Comp Tech Conf, pp 521-536, 1986.

8. Hiller, C.C. and Glicksman, L.R., Compresgor Capacity Control via Early SuctionValve Clogino, Proc Purdue Comp Tech Conf, pp 137-140, 1976.

9. Korsgaard, A., Automatic Capacity Regulation of Refrigerating Compressorg, Proc XII Int Cono Refrigeration, paper 3.40, Madrid 1967.

10. Boyd, D.L., Capacity Control of Reciprocating Compressors Used in Refrigeration Systems, proc Purdue Comp Tech Conf, pp 37-43, 1972.

11. White, K.H., Infinitely Variable Capacity Control, Proc Purdue Comp Tech Conf, pp $47-51,1972$,

12. Ehrlich, F.J., Blocked Suction Unloading Improveg Part Load Efficlency of SemiHermetic Reciprocating Compressor, Proc Purdue Coup Tech Conf, pp 56-60, 1986.

13. Cheney, L.W., A New Approach to Compressor Capacity Modulation, Proc Purdue Comp Tech Conf, pp 55-60, 1974 .

14. Hartwick, W., Power Requirements and Assocjated Effects of Reciprocating Comprespor Cylinders Ends Deactivated by Internal Bypassing, Proc Purdue Comp Tech Conf. pp 141$149,1976$.

15. Haseltine, J.D. and Qvale, E.B., Comparison of Power and Efficiency of CongtantSpeed Compresgors Uaing Three Different Capacity Reduction Methods, ASHRAE Trang, $\mathrm{v} 77$ I, paper 2182, pp 158-162, 1971.

16. Hiller, C.C. and Glicksman, L.R., Compresgor Capacity Control, in "Heat pump Technology For Saving Energy", Collie, M.J., Editor, pp 276-333, Noyes Data Corp, 1979. 17. Tasgou, S.A., Marquand, C.J. and Wilson, D.R. . The Effects of Capacity Modulation on the Performance of Vapour Compregsion Heat Pump Sygtems, Int Symp Industrial Application of Heat Pumpg, pp 187-196, Warwick, U.K., 1982.

18. Parise, J.A.R and Cartwright, W.G., Performance Characteristics of a High Temperature Water-to-water Heat Pump, to appear in Jnl Energy Research.

19. Neale, D.F., Wano, Y.T., Wilson, D.R., Green, R.K. and Searle, M., Microprocegsor Based Control System for Heat Pumps, Third Int Conf Future Eneroy Concepts, IEE Conf
192, op 238-241, London 1981 .

20. PariBe, J.A.R. and Cartwright, W.G., simulation of Reciprocating Compressors: Numerical Method and Comparison with Experimental Data, Revista Brasileira de Ciencias
Mecanicas, VII-2, pp 129-152, 1985.

21. Gatecliff, G.W. and Lady, E.R., Explicit Representation of the Thermodynamic Propertieg of Refrigerants 12 and 22 in the Superheat Region, Proc Purdue Comp Tech
Conf, pp 287-290, 1974.

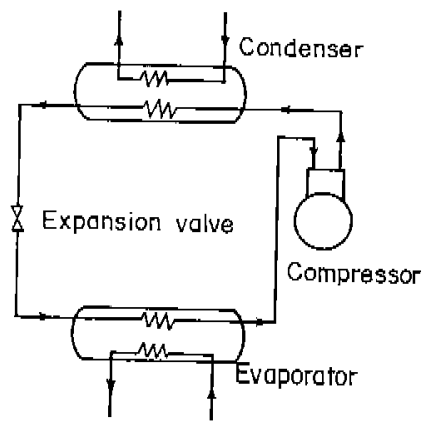

Fig. 1 Vapour-Compression Heat Pump Syatem.

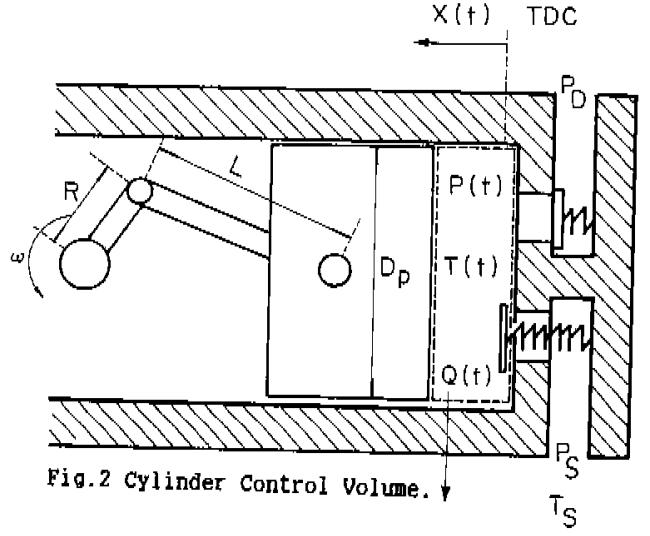




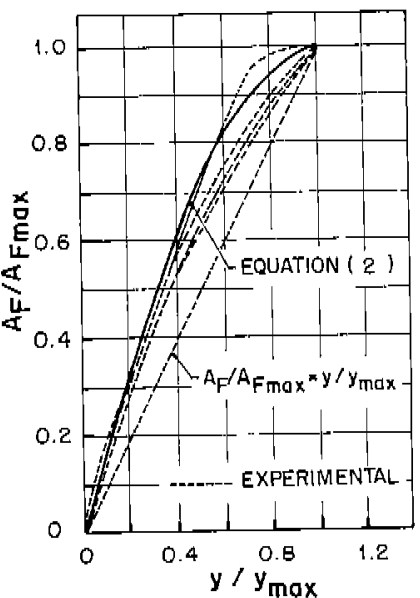

Fig. 3 Valve Effective Flow Area vs. Valve Displacement
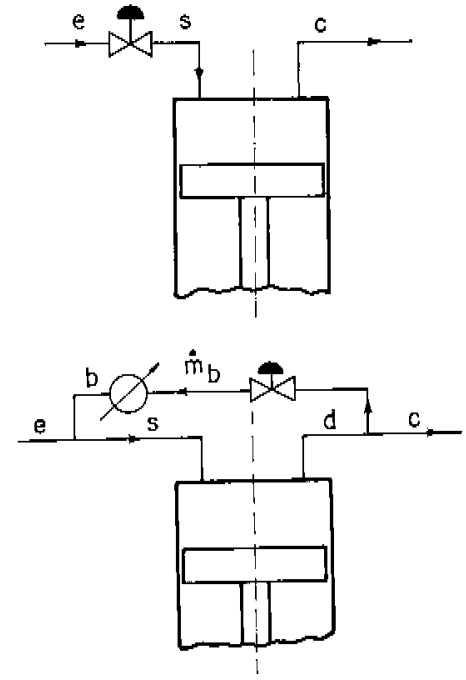

Fig. 4 (a) Suction Throttling: (b) Gas By-Pagsing.
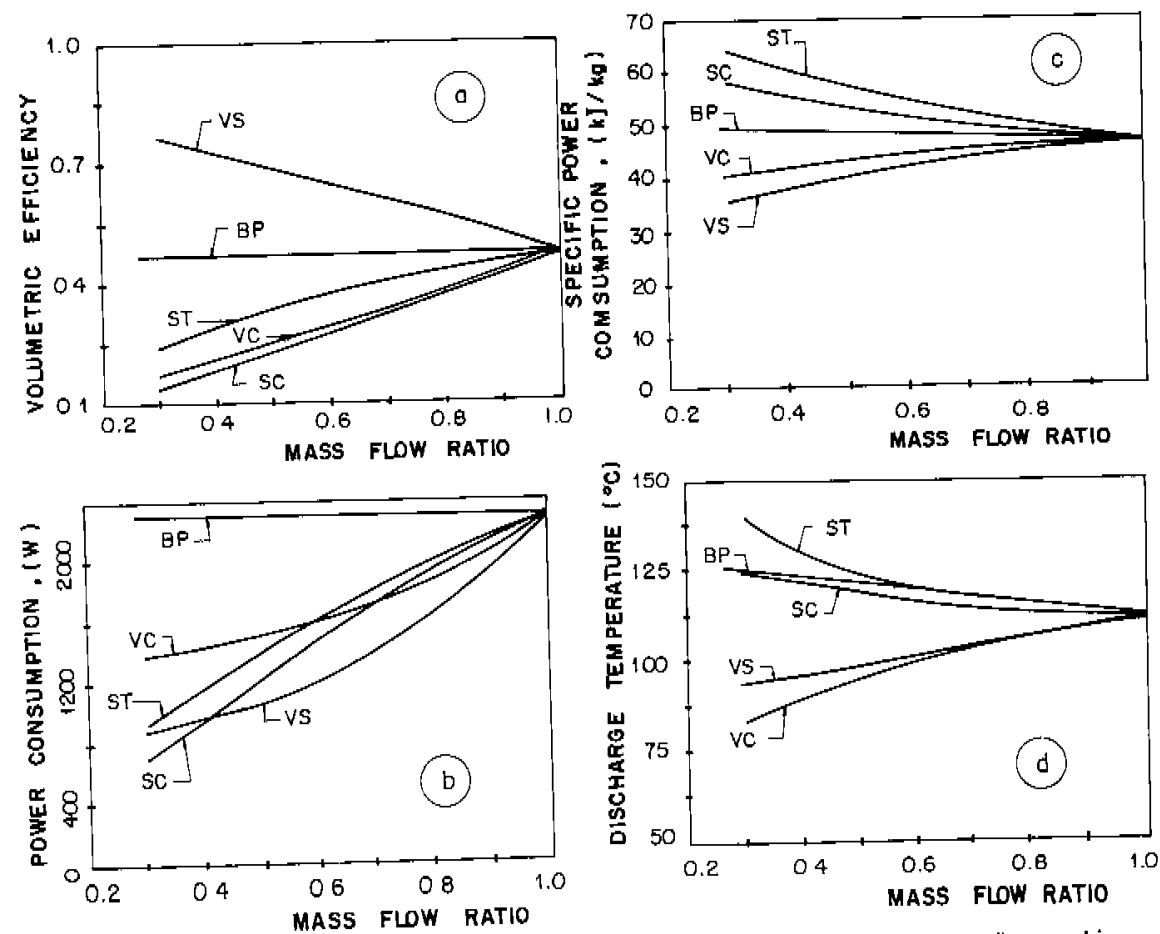

Fio.5 Effect of Capacity Control on: a) Volunetric Efficiency; b) Power Consumption; c) Specific Power Congumption: d) Digcharge Temperature. ST: Suction Throttling; SC: Suction Valve Cut-off; BP: Discharge Gas By-Pasging; VC: Variable Clearance Volume; VS: Variable Speed. 


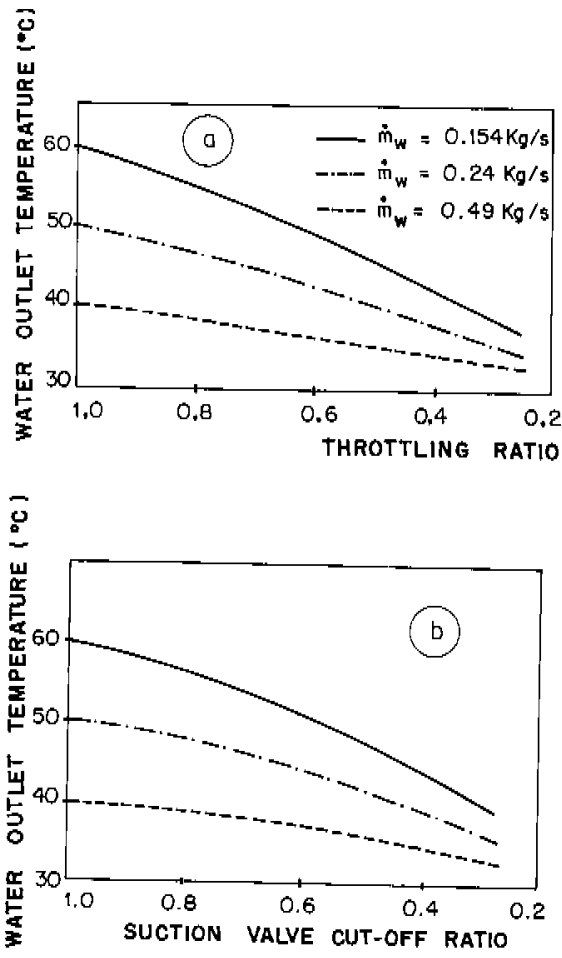

Fig. 6 Control of Hot Water Tenperature with: a) Suction Throttling; b) Suction Valve Cut-off; c) Discharge Gas By-Pass; d) Variable Clearance Volume; e) Variable Shaft Speed.
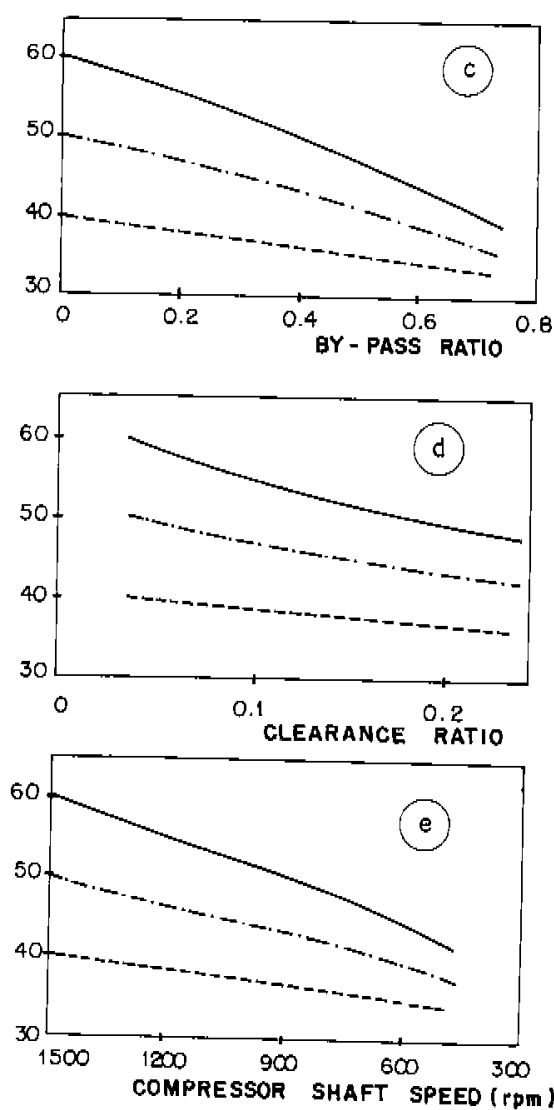

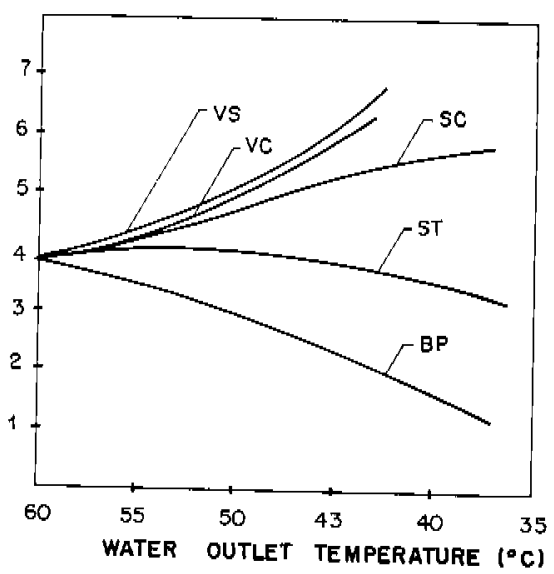

Fig.7 Heat Pump Cop vo, Condenger Water Outlet Temperature

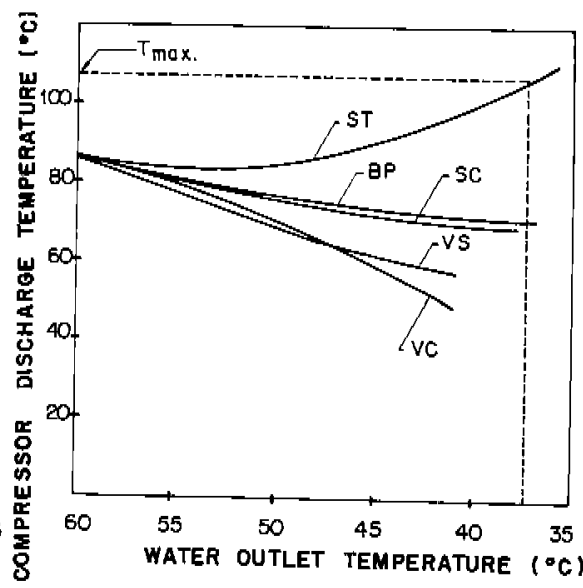

Fio.8 Compressor Discharge Tenperature va. water outlet Temperature 